\title{
Miscarriage and early first trimester growth restriction by ultrasound
}

\author{
Neelima Agarwal *, Amita Sharma
}

Department of Obstetrics and Gynaecology, Santosh Medical College and Hospital, Santosh University, Ghaziabad, Uttar Pradesh, India

Received: 09 March 2016

Accepted: 04 April 2016

\section{*Correspondence:}

Dr. Neelima Agarwal,

E-mail: agarwalneelima2@gmail.com

Copyright: ( ) the author(s), publisher and licensee Medip Academy. This is an open-access article distributed under the terms of the Creative Commons Attribution Non-Commercial License, which permits unrestricted non-commercial use, distribution, and reproduction in any medium, provided the original work is properly cited.

\section{ABSTRACT}

Background: Concern about the possibility of spontaneous miscarriage is one of the most common reasons women seek evaluation in the emergency department during their first trimester. According to the obstetrics and gynecology literature, it is estimated that $20 \%$ to $25 \%$ of all clinically recognized pregnancies result in spontaneous miscarriage. The objective of the study is to examine with whether viable early pregnancies that subsequently end in miscarriage exhibit evidence of first-trimester growth restriction. The prospective cohort study design used for this purpose with setting of Antenatal clinic of a teaching hospital. Women attending the clinic between 5 and 10 weeks of gestation took part in the study.

Methods: Women with spontaneously conceived intrauterine, viable singleton pregnancies with certain last menstrual period and regular cycles were included. The deviation between the observed and expected crown-rump length (CRL) for gestation was calculated and expressed as a z-score. Pregnancies were followed up until 11-14 weeks, and the deviation between those that remained viable and miscarried subsequently was calculated. Viability at 11-14 weeks was measured.

Results: Over 12 months, 320 women met the inclusion criteria. Twenty women were excluded. Of the remaining 300 , the pregnancy remained viable in $248(82.6 \%)$ and $52(17.4 \%)$ suffered a miscarriage. At the first transvaginal ultrasound, the $\mathrm{z}$ score of the mean measured CRL for pregnancies that remained viable was -0.69 while in pregnancies that subsequently miscarried the z-score was -2.95 and the CRL was significantly smaller $(\mathrm{P}<0.048)$. In the latter group, the initial CRL was below the expected mean for gestational age in all women.

Conclusions: CRL was significantly smaller in pregnancies that subsequently ended in miscarriage. This suggests that early first trimester growth restriction is associated with subsequent intrauterine death.

Keywords: Early pregnancy, Growth restriction, Miscarriage, Ultrasound

\section{INTRODUCTION}

Concern about the possibility of spontaneous miscarriage is one of the most common reasons women seek evaluation in the emergency department during their first trimester. According to the obstetrics and gynaecology literature, it is estimated that $20 \%$ to $25 \%$ of all clinically recognized pregnancies result in spontaneous miscarriage. ${ }^{1}$ Once a viable foetus is diagnosed by ultrasonography, however, the rate of spontaneous miscarriage subsequently decreases to $3 \%$ to $6 \%$. If an embryo has developed up to $5 \mathrm{~mm}$ in length, subsequent loss of viability occurs in $7.2 \%$ of cases. Loss rates drop to $3.3 \%$ for embryos of $6-10 \mathrm{~mm}$ and to $0.5 \%$ for embryos over $10 \mathrm{~mm}^{2}$

Early pregnancy dating by crown to rump length (CRL), rather than estimation of gestation from last menstrual period (LMP) dates, is commonly performed to date pregnancies up to 14 weeks, assuming no growth variation.

Previous studies have shown that the observed CRL in pregnancies destined to miscarry is smaller than that 
expected for gestational age. In one study, there was an increased likelihood of miscarriage with increasing discrepancy between observed and expected CRL; $13.7 \%$ of foetuses with a CRL more than 2SD below that expected for gestational age miscarried compared with an $8.3 \%$ miscarriage rate in those with less than 2SD difference. $^{3}$

One possible link between a small CRL and subsequent miscarriage is that chromosomal defects not only have a high intrauterine lethality rate but can also be associated with foetal growth restriction in the first trimester of pregnancy. 4

The aim of this study was to prospectively assess whether spontaneously conceived, viable singleton pregnancies from an 'outpatient antenatal clinic' population, which subsequently end in miscarriage, exhibit a different pattern of growth from those that remain viable.

\section{METHODS}

The present prospective study was conducted in the department of obstetrics and gynaecology, Santosh medical and dental college hospitals, Ghaziabad, Uttar Pradesh, India to evaluate adverse pregnancy outcome in patients with early first-trimester growth restriction as observed ultrasonologically.

All women with viable singleton intrauterine pregnancies at 5-10 completed weeks of gestation, calculated from the last menstrual period (LMP) were included.

Women with history of multiple pregnancy, women conceived by ART, extra uterine, non-viable or molar pregnancy, women not sure of menstrual dates, history of hormonal contraception or intrauterine contraceptive device usage, pregnancy or breast feeding in the 3 months preceding the current pregnancy or documented uterine anomalies were excluded from the study.

The study was approved by the ethical committee of the Santosh University, Ghaziabad, Uttar Pradesh, India. All women attending the antenatal clinic were offered the option of being included in this prospective observational study. Those who agreed were asked to complete a questionnaire including demographic features, detailed obstetric and menstrual histories and pregnancy symptoms. All women underwent a TVS as part of the pregnancy assessment to determine location, viability and gestation. In viable pregnancies, the number of embryos was documented and measurement of embryonic CRL performed.

Initially, 320 patients were included in the study, 20 patients were lost to follow up. Hence, study was conducted over 300 patients.

The primary outcome was continuing viability of the pregnancy beyond the first trimester, as determined by viability at the routine 11-14 week ultrasound assessment or known viability at a later gestation.

\section{Statistical Analysis}

To compare the differences in CRL between those pregnancies that remained viable and those that subsequently miscarried, the deviation of observed and expected CRL was calculated. The observed CRL was established from the initial ultrasound examination. The expected CRL was calculated based on established growth curves of gestational age and CRL. These growth curves had been well validated using the transvaginal route. The difference between the observed and expected CRL was calculated and expressed in SDs (z-score). Continuous variables between groups, including the $\mathrm{z}$ scores were compared. Sensitivity, specificity, positive predictive value (PPV) and negative predictive value (NPV) for the prediction of subsequent pregnancy loss following a scan demonstrating a CRL below -2 SD from the expected mean were calculated. Two sided $\mathrm{P}$ values were reported throughout.

\section{RESULTS}

In our study, over 1 year, 320 women met the inclusion criteria. Twenty women were lost to follow up. Of the remaining 300, the pregnancy remained viable in 248 $(82 \%)$ and $52(18 \%)$ suffered a miscarriage between their initial presentation and the 11-14 week scan (Table-1).

Table 1: Comparison of pregnancy outcome.

\begin{tabular}{|lccc|}
\hline $\begin{array}{l}\text { Pregnancy } \\
\text { outcome }\end{array}$ & $\begin{array}{c}\text { Number } \\
\text { of cases }\end{array}$ & $\begin{array}{c}\text { Total number } \\
\text { of cases }\end{array}$ & $\begin{array}{l}\text { Percentage } \\
(\%)\end{array}$ \\
\hline $\begin{array}{l}\text { Remain } \\
\text { viable }\end{array}$ & 248 & 300 & $82 \%$ \\
\hline $\begin{array}{l}\text { Subsequent } \\
\text { miscarriage }\end{array}$ & 52 & 300 & $18 \%$ \\
\hline
\end{tabular}

There was no statistically significant difference between maternal characteristics, parity or obstetric history between those women who subsequently suffered a miscarriage when compared with women in whom pregnancies remained viable.

No significant difference was seen in likelihood of miscarriage between those initially presenting with pain alone, bleeding alone, pain and bleeding or neither pain nor bleeding (P 0.56) (Table 2).

The mean z-score for CRL in pregnancies that remained viable was -0.69 (SD 4.17), while in those that subsequently miscarried, the mean $\mathrm{z}$-score for CRL was significantly larger at $-2.95(\mathrm{SD} 1.04, \mathrm{t}=1.99, \mathrm{P}<$ 0.048). In the latter group, the initial CRL was below the expected mean for gestational age in all women. 
Table 2: Comparison according to symptoms.

\begin{tabular}{|c|c|c|c|}
\hline Indication & $\begin{array}{l}\text { Remain } \\
\text { viable } \\
(n=248)\end{array}$ & $\begin{array}{l}\text { Subsequent } \\
\text { miscarriage } \\
(n=52)\end{array}$ & P-value \\
\hline Bleeding & $30(12 \%)$ & $15(29 \%)$ & \multirow{5}{*}{0.56} \\
\hline Pain & $78(32 \%)$ & $13(25 \%)$ & \\
\hline $\begin{array}{l}\text { Bleeding and } \\
\text { pain }\end{array}$ & $20(8 \%)$ & $14(27 \%)$ & \\
\hline Anxiety & $100(40 \%)$ & $8(15 \%)$ & \\
\hline Others & $20(8 \%)$ & $2(4 \%)$ & \\
\hline
\end{tabular}

All pregnancies that subsequently miscarried had a CRL below the expected CRL for gestation, and in 52\% (27/52), the CRL was 2 SDs or more below that expected for gestational age. In 26\% (66/248), pregnancies that remained viable, the CRL was 2 SDs or more below the expected CRL. We have shown that the risk of subsequent miscarriage increases with increasing deviation from the expected CRL. Thus, while the risk of miscarriage is $12 \%$ in those with CRL within 2 SDs, the risk is 16,41 and $75 \%$ for those with a CRL between -2 and -3 SDs, -3 and -4 SDs and more than -4 SDs, respectively (Table 3$)$.

Table 3: Comparison of deviation of CRL and subsequent outcome.

\begin{tabular}{|llll|}
\hline Z-score & $\begin{array}{l}\text { Remain } \\
\text { viable } \\
(\mathrm{n} \%)\end{array}$ & $\begin{array}{l}\text { Subsequent } \\
\text { miscarriage } \\
(\mathrm{n} \%)\end{array}$ & $\begin{array}{l}\text { Percent } \\
\text { subsequent } \\
\text { miscarriage } \\
(\%)\end{array}$ \\
\hline $\mathbf{- 2}$ or more & $182(73 \%)$ & $25(48 \%)$ & $12 \%$ \\
\hline $\begin{array}{l}\mathbf{- 3} \text { to less } \\
\text { than -2 }\end{array}$ & $47(19 \%)$ & $9(17 \%)$ & $16 \%$ \\
\hline $\begin{array}{l}\mathbf{- 4} \text { to less } \\
\text { than }-3\end{array}$ & $17(7 \%)$ & $12(23 \%)$ & $41 \%$ \\
\hline $\begin{array}{l}\text { Less than } \\
\mathbf{- 4}\end{array}$ & $2(1 \%)$ & $6(12 \%)$ & $75 \%$ \\
\hline Total & 248 & 52 & \\
\hline
\end{tabular}

There was a relationship between increasing CRL deviation, z-score and miscarriage; with the risk of miscarriage increasing with increasing CRL deviation. Using a CRL measurement below 2 SDs as a cut off in predicting subsequent miscarriage yielded a sensitivity of $51.9 \%$, with a specificity of $67.6 \%$, PPV of $29 \%$ and NPV of $87 \%$

\section{DISCUSSION}

In this study, we have demonstrated, that, in women with spontaneously conceived, singleton pregnancies and certain menstrual dates, who attended the antenatal clinic, the CRL is below that expected for gestation in all cases that will subsequently miscarry, ranging from -2 or more SDs to -4 or less SDs. Eighty-one percent of the continuing pregnancies also had a CRL, which was less than that expected by gestational age, despite women only having been included, if they had certain dates and regular cycles. This phenomenon of women overestimating gestational age, has been reported before, and, is likely to be attributed to late ovulation or inaccurate reporting of LMP date. ${ }^{5}$ However, in viable continuing pregnancies, the mean deviation between the observed and expected CRL was $26 \%$, while it was $52 \%$ in those pregnancies that subsequently miscarried.

It is known that at least $70 \%$ of first-trimester losses are due to chromosomal abnormalities, and, that, these can be associated with early growth delay. ${ }^{4}$ However, a study showed that the growth delay in foetuses, prior to miscarriage, was similar in both foetuses with normal and abnormal karyotype. ${ }^{1}$ Thus, although the reason for the slower rate of foetal growth might be attributable to chromosomal abnormality in the majority, there may be another etiology that affects karyotypically normal foetuses that miscarry. One possibility is that abnormal placentation could play a role; histological examination in cases of early pregnancy loss has shown a thinner and more fragmented trophoblastic shell and reduced cytotrophoblastic invasion of spiral arteries, than in normal pregnancy; which eventually leads to indirect oxidative stress effects and cellular dysfunction. ${ }^{6}$ It is possible, that, embryonic growth could be affected through this process, representing an early manifestation of placental dysfunction.

In our study, the rate of miscarriage after visualization of a positive foetal heart action was $12 \%$. One study demonstrated, that, the rate of miscarriage after visualization of foetal heart is higher in women with threatened miscarriage, when compared with a control group without bleeding (5.5 versus $1.9 \%) .^{2}$ In our study, we did not find that women were more likely to have an early miscarriage if they presented with bleeding, once the foetal heart was visualized in early pregnancy.

As in our study, earlier studies have also reported, that, many pregnancies with normal outcome are also found to have a CRL or GS size that is less than expected. ${ }^{7,8,9}$ This is in part due to the fact, that, when using cross-sectional data to assess foetal size, gestational age assessment relies on accurate recall of the last menstrual period (LMP). ${ }^{7}$ It is known, that, reporting of LMP is susceptible to bias, with a general tendency for women to overestimate their gestational age ${ }^{5}$ and thus be found to have a discrepancy between observed and expected foetal size measurements. Even in those with known LMP and regular cycles there is a discrepancy of more than 5 days in gestation calculated from the menstrual history and by ultrasound in about $25 \%$ of cases. ${ }^{8}$

In one retrospective study, the predictive accuracy of CRL discordance for single foetal loss was high (AUC $=0.93 ; 95 \%$ CI $=0.91-0.94)$. A significant association was found between the increase in the degree of embryonic discordance and the likelihood of early fetal loss $(\mathrm{P}<0.0001) .^{10}$ 
One study recently reported that a small-for-gestationalage 3D gestational sac volume was a novel sonographic predictor of subsequent miscarriage. ${ }^{11}$

Our study suggests that, despite many women overestimating their gestational age, smaller-thanexpected CRL may also be a sign of early foetal growth delay. We have shown, that, the risk of subsequent miscarriage increases with increasing deviation from the expected CRL.

\section{CONCLUSIONS}

This prospective study confirms that the first trimester growth rate of pregnancies destined to miscarry is significantly lower than in those that remain viable. In women with certain LMP, CRL for gestation was smaller in pregnancies that subsequently ended in miscarriage than in those that remained viable. All pregnancies that ended in miscarriage had a CRL below that expected for gestation, and in fifty-two percent, the CRL was at least 2 SD below expected CRL.

\section{ACKNOWLEDGEMENTS}

I pay my profound regards to the faculty of Radiology department and my co-faculty in the department of obstetrics gynaecology of Santosh University, Ghaziabad, Uttar Pradesh, India for their constant support and immeasurable help.

The debt I owe to my patients is supreme and cannot be explained merely in words

Funding: No funding sources

Conflict of interest: None declared

Ethical approval: The study was approved by the Institutional Ethics Committee

\section{REFERENCES}

1. Zinaman MJ, Clegg ED, Brown CC, O'Connor J, Selevan SG. Estimates of human fertility and pregnancy loss. Fertil Steril. 1996;65:503-9.

2. Jauniaux E, Johns J, Burton GJ. The role of ultrasound imaging in diagnosing and investigating early pregnancy failure. Ultrasound Obstet Gynecol. 2005;25:613-24.

3. Reljic M. The significance of crown-rump length measurement for predicting adverse pregnancy outcome of threatened abortion. Ultrasound Obstet Gynecol. 2004;17:510-2.

4. Goldstein SR, Kerenyi T, Scher J, Papp C. Correlation between karyotype and ultrasound findings in patients with failed early pregnancy. Ultrasound Obstet Gynecol. 1996;8:314-7.

5. Savitz DA, Terry JW, Dole N, Thorp JM, Siega-Riz AM, Herring AH. Comparison of pregnancy dating by last menstrual period, ultrasound scanning and their combination. AmJ Obstet Gynecol. 2002;187:1660-6.

6. Bottomley C, Daemen A, Mukri F, Papageorghiou AT, Kirk E, Pexsters A, et al. Assessing first trimester growth: the influence of ethnic background and maternal age. Hum Reprod. 2009;24(2):284-90.

7. Mukri F, Bourne T, Bottomley C, Schoeb C, Kirk E, Papageorghiouet AT. Evidence of early first trimester growth restriction in pregnancies that subsequently end in miscarriage. BJOG. 2008;115:1273-8.

8. Papaioannou GI, Syngelaki A, Poon LCY, Ross JA, Nicolaides KH. Normal ranges of embryonic length, embryonic heart rate, gestational sac diameter and yolk sac diameter at 6-10 weeks. Fetal Diagn Ther. 2010;28:207-19.

9. Abuelghar WM, Fathi HM, Ellaithy MI, Anwar MA. Can a smaller than expected crown-rump lengths reliably predict the occurrence of subsequent miscarriage in a viable first trimester pregnancy? J Obstet Gynaecol Res. 2013;39(10):1449-55.

10. D'Antonio F, Khalil A, Mantovani E, Thilaganathan B. Southwest Thames Obstetric Research Collaborative. Embryonic growth discordance and early fetal loss: the STORK multiple pregnancy cohort and systematic review. Hum Reprod. 2013;28(10):2621-7.

11. Wie JH, Choe S, Kim SJ, Shin JC, Kwon JY, Park IY. Sonographic parameters for prediction of miscarriage: role of 3-dimensional volume measurement. J Ultrasound Med. 2015;34(10):177784.

Cite this article as: Agarwal N, Sharma A.

Miscarriage and early first trimester growth restriction by ultrasound. Int J Reprod Contracept Obstet Gynecol 2016;5:1558-61. 